\title{
Mortality in Italian patients with rheumatoid arthritis: evidence for a low mortality rate from cancer and infections in patients followed up at a tertiary center
}

\author{
This article was published in the following Dove Press journal: \\ Open Access Rheumatology: Research and Reviews \\ 3 November 2017 \\ Number of times this article has been viewed
}

\section{Daniela lacono \\ Serena Fasano \\ Virginia D'Abrosca \\ Ilenia Pantano \\ Gabriele Valentini \\ Department of Clinical and Experimental Medicine, Rheumatology Section, University of Campania "Luigi \\ Vanvitelli," Naples, Italy}

Objectives: Mortality in patients with rheumatoid arthritis (RA) has never been investigated in Italy. This study is devoted to investigating all the distinct causes of mortality in Italian RA patients.

Methods: Clinical charts of patients consecutively admitted to an Italian tertiary center, from January 1, 2008 to December 31, 2014, were reviewed. Mortality rates (incidence mortality rate [IMR] and standardized mortality rate [SMR]) and causes of death as assessed at December 31, 2015, were registered. Mortality rates detected in our series were compared to those reported in other European cohorts and in the general Italian population.

Results: Six hundred and eight patients were observed for a median of 3.51 years. Overall IMR was 0.79 deaths/ 100 person-years. No significant difference between our IMR and that reported in Italian population by the National Institute of Statistics was observed. All-cause and neoplasm IMRs in our series were found to be significantly lower than that reported in the Norfolk Arthritis Registry, while no difference was detected in cardiovascular (CV) mortality. On the other hand, all causes and CV SMRs in our series were found to be higher than that reported in the general Italian population, while cancer and infectious SMRs were found to be lower.

Conclusion: In our series, RA patients had an increased all-cause mortality, and in particular an increased death rate due to $\mathrm{CV}$. However, a lower death rate due to cancer and infections was observed. This figure might be due to the careful follow-up of RA patients in tertiary centers, and the results underlines the need to improve the management of CV risk.

Keywords: rheumatoid arthritis, mortality, cancer, infections, cardiovascular deaths

\section{Introduction}

Rheumatoid arthritis (RA) is a chronic systemic inflammatory disorder associated with increased mortality from all causes, in particular from cardiovascular disease (CVD), infections and cancer. ${ }^{1-5}$

A recent meta-analysis demonstrated that RA mortality has decreased over the past years. Nevertheless, it remained higher than in the general population with a metastandardized mortality rate (SMR) of $1.47 .^{6}$

To the best of our knowledge, no data are available on RA mortality in Italy. These data are warranted because:
Correspondence: Serena Fasano Medicine, Rheumatology Section, University of Campania "Luigi Vanvitelli," II Policlinico, Via Pansini 5, 80I3I Naples, Italy

Tel +39 08I 5464487

Fax $+3908 I 5666747$

Email serena.fasano@unicampania.it 
1. CV mortality in RA has distinct patterns among different countries. $^{5}$

2. RA has been reported to present both a lower prevalence and as a milder disease course in Italy and in other Mediterranean countries with respect to North European countries..$^{7-11}$

In that regard, it is noteworthy that Italy had the lowest use of biologics in Western Europe, further supporting the existence of differences in disease severity between Northern and Southern European countries, including Italy. ${ }^{12}$

The aim of this study was to investigate the mortality rate and predictive factors, as assessed at admission, in a cohort of RA patients followed at an Italian tertiary center of rheumatology.

\section{Methods}

\section{Patients}

The study subjects consisted of patients consecutively admitted to the Rheumatology Unit of the Second University of Naples from January 1, 2008 to December 31, 2014, satisfying at admission the American College of Rheumatology/ European League Against Rheumatism (ACR/EULAR) 2010 criteria. $^{13}$

Age, sex, disease duration, autoantibody profile, disease activity, disability, concomitant comorbilities, and concomitant treatment as derived from medical records at baseline were noted.

Disease duration (in years) was assessed from the first symptom ascribed to the disease. Serum rheumatoid factor (cut off 20 units $/ \mathrm{mL}$ ) and anti-citrullinated cyclic peptide antibodies (enzyme-linked immnosorbent assay test, cut off 25 units $/ \mathrm{mL}$ ) were used to subdivide patients into seropositive and seronegative subgroups. Disease activity was evaluated by using the Simplified Disease Activity Index. Disability was assessed by using the Health Assessment QuestionnaireDisability Index (HAQ-DI). ${ }^{14,15}$

Each patient was investigated for arterial hypertension (prior/ongoing and/or antihypertensive therapy use), diabetes mellitus (fasting glucose level $>126 \mathrm{mg} / \mathrm{dL}$ in at least two tests and/or ongoing treatment with insulin or oral hypoglycemic agents), and metabolic syndrome (based on 1998 World Health Organization criteria). ${ }^{16}$

Previous CV events were defined by history of coronary events and/or cerebrovascular accident and/or atherosclerotic peripheral ischemia.

Finally, baseline concomitant drugs and follow-up intervening treatments subdivided into biological and nonbio- logical disease-modifying antirheumatic drugs (DMARDs) were considered.

On December 31, 2015, vital status and causes of death of the patients were identified. In particular, deaths by CVD, cancer, infections, and other causes were considered.

The mortality rate was expressed as the number of deaths in the cohort divided by the number of years of follow-up (deaths/person-years of observation-incidence mortality rate [IMR]). It was compared with that reported in the Norfolk Arthritis Register (NOAR), a British registry which included 678 RA patients who were DMARD-naive and with symptom onset of $<2$ years at the time of inclusion to the study. ${ }^{17}$

Although the inclusion years were different, NOAR was chosen as comparator because in that registry the death data provided were until December 2014, similar to the end of our observation period (December 2015). SMR (observed deaths/expected deaths) was calculated using mortality data deduced from the National Institute of Statistics (ISTAT), to assess the overall mortality of the study group compared with the general Italian population. ${ }^{18}$

Written informed consent was obtained from all patients, according to the Declaration of Helsinki.

The study was approved by the Ethics Committee of the Second University of Naples.

\section{Statistical analysis}

Continuous variables were analyzed with the Mann-Whitney test, while $\chi^{2}$ test or Fisher's exact test was applied for categorical variables.

The comparison of mortality rates was conducted as comparison of IMRs. SMR was calculated by a ratio between observed and expected deaths, stratifying patients by sex and age and calculating the number of follow-up years for each patient in every interval of age; expected number of deaths was obtained by multiplying the total number of follow-up years in each interval of age by the mortality rate of the general population for the same interval. SMR confidence intervals were calculated by Mid- $P$ exact test. Univariate Cox regression analysis served to identify factors associated with mortality in the overall cohort. Factors found to be significant in univariate analysis were entered in the multivariable model. A $p$-value $<0.05$ was considered significant.

Statistical analysis was performed with MedCalc, version 12.7.0.0.

\section{Results \\ Baseline data}

Data from 654 patients were retrospectively analyzed. 
Table 1 shows epidemiological, serological, and clinical features of the 654 patients included in the study. Out of them, $470(72 \%)$ were female; the mean $( \pm \mathrm{SD})$ age was $55.7 \pm 12.4$ years (median: 56.80 ; range: $15-89.5$ ); the mean $( \pm \mathrm{SD})$ disease duration at the first visit at the center was 10.3 \pm 8.3 (median: 9; range: 0.5-41).

Serological data were available for 460 patients; out of them 319 patients were positive for rheumatoid factor and/or anti-citrullinated cyclic peptide antibodies (69.1\%).

As assessed at the first visit in all the patients, Simplified Disease Activity Index ranged from 0.02 to 45 (mean \pm SD: 13.7 \pm 9.68 ; median: 12.19 ; range: $0.02-45$ ) and HAQ-DI from 0 to 3 (mean $\pm \mathrm{SD}$ : $1.13 \pm 0.79$; median: 1 ; range: $0-3$ ).

Two hundred and sixty-four patients $(40.5 \%)$ were suffering from arterial hypertension 54 (8.4\%) suffered from diabetes, 68 (10.4\%) satisfied the 1998 World Health Organization criteria for metabolic syndrome, and $29(4.4 \%)$ had a history of CV events ( 17 myocardial ischemia, 5 unstable angina, 4 cerebrovascular accident, and 3 atherosclerotic peripheral ischemia).

During the follow-up, all the patients had been managed according to the treat-to-target strategy: $58 \%$ had been treated with biological DMARDs with or without conventional DMARDs, while $42 \%$ were treated with conventional DMARDs only. In particular, $53 \%$ of whole cohort was treated with methotrexate, while $43 \%$ were administered low-dose glucocorticoids.

\section{Follow-up}

On December 31, 2015, 46 patients had been lost to follow-up (7\%). The remaining 608 patients had been observed for a

Table I Baseline features of the 654 RA patients

\begin{tabular}{|c|c|}
\hline Features & Value \\
\hline Sex F/M ratio & $470(72 \%) / / 84(28 \%)$ \\
\hline Age in years (median, range) & $56,80(15-89.5)$ \\
\hline Mean \pm SD & $55.7 \pm 12.4$ \\
\hline $\begin{array}{l}\text { Disease duration in years from } \\
\text { onset (median, range) }\end{array}$ & $9(0.5-4 I)$ \\
\hline Mean \pm SD & $10.3 \pm 8.3$ \\
\hline $\mathrm{RF}+(\%)$ & $270 / 432(62.5 \%)$ \\
\hline $\mathrm{ACPA}+(\%)$ & $188 / 360(52.2 \%)$ \\
\hline $\mathrm{RF}$ and/or ACPA & $319 / 460(69.1 \%)$ \\
\hline SDAI (median, range) & $12.19(0.02-45)$ \\
\hline Mean \pm SD & $13.7 \pm 9.68$ \\
\hline HAQ-DI (median, range) & I (0-3) \\
\hline Mean \pm SD & $1.13 \pm 0.79$ \\
\hline Hypertension, n (\%) & $264 / 654$ (40.5); 74\% F, 26\% M \\
\hline Diabetes, n (\%) & $54 / 654$ (8.4); 63\% F, 37\% M \\
\hline Metabolic syndrome, n (\%) & $68 / 654$ (I0.4); 70.6\% F, 29.4\% M \\
\hline CV events, n (\%) & $29 / 654(4.4)$ \\
\hline
\end{tabular}

Abbreviations: RA, rheumatoid arthritis; RF, rheumatoid factor; ACPA, anticitrullinated cyclic peptide antibodies; SDAI, Simplified Disease Activity Index; HAQ-DI, Health Assessment Questionnaire-Disability Index; CV, cardiovascular. median of 3.51 years (range $0.21-7.96$ ). Out of them, 19 had died (case fatality rate 3.12\%): 11 (58\%) from CVD, $4(21 \%)$ from malignancy (a 70 years old man died of lymphoma, a female patient died of bladder cancer at the age of 57 years, another female patient died of breast cancer at the age of 60 years, and a 68 years old woman died of melanoma), 3 (16\%) from respiratory diseases (respiratory failure secondary to interstitial lung disease in one case and bronchopulmonary chronic obstructive disease in the others), and one from unknown causes $(5.3 \%)$; none of them died due to infections. New cases of cancer occurred in 30 patients (nine cases of breast cancers; three cases of non-Hodgkin lymphoma, prostatic, thyroid, and bladder cancers each; two cases of lung and cervical uterus cancers each; one case of pancreatic, colonic, renal, laryngeal, and neuroendocrine cancer each). Severe infections occurred in eight patients (six pneumonia, one meningitis, and one active tuberculosis). Patients lost to follow-up were contacted by phone to ascertain vital status.

\section{Mortality rates}

In our series, overall IMR was 0.79 deaths/100 person-years; neoplasm-attributed IMR was 0.17 , while $\mathrm{CV}$-attributed IMR was 0.46 .

No significant differences emerged between the IMR detected in our series and that reported in the general Italian population by ISTAT ( 0.79 deaths/100 person-years vs 1 death/100 person-years; $p$ : $0.292 ; 95 \%$ confidence interval [CI]: 0.473-1.2271). ${ }^{18}$

Moreover, all-cause and neoplasm IMR in our series were found to be significantly lower than that reported in the NOAR registry: IMR for all causes 0.79 deaths/ 100 personyears vs 2.17 in the NOAR $(p<0.009)$; IMR for neoplasm 0.17 deaths $/ 100$ person-years vs 0.59 in the NOAR $(p<0.001)$. However, no difference emerged between our study and NOAR series in IMR by CVD (Table 2). We did not detect any death due to infectious disease. ${ }^{17}$

Despite the previous results, SMR in our series was found to be higher than that reported in the general Italian population (SMR: 1.89; 95\% CI: 1.17-2.89). Sex-adjusted SMRs were 2.5 for males and 2.04 for females, pointing to a greater mortality in males.

Table 2 IMR in our series compared with NOAR cohort

\begin{tabular}{llll}
\hline & Our cohort & NOAR & $P$-value \\
\hline All-cause IMR & 0.79 & 2.17 & $<0.0001$ \\
CV-IMR & 0.46 & 0.73 & 0.1599 \\
Neo-IMR & 0.17 & 0.59 & 0.0099 \\
\hline
\end{tabular}

Abbreviations: IMR, incidence mortality rate; NOAR, norfolk arthritis register; CV, cardiovascular; Neo, Neoplasm. 
Table 3 Predictive factors of mortality on univariate analysis

\begin{tabular}{lll}
\hline Feature & HR (95\% CI) & P-value \\
\hline Age & $\mathrm{I} .14(\mathrm{I} .08-\mathrm{I} .20)$ & $<0.000 \mathrm{I}$ \\
Disease duration & 0.974 & 0.358 \\
RF positivity & $\mathrm{I} .73$ & 0.502 \\
ACPA positivity & $\mathrm{I} .2$ & 0.810 \\
SDAI & 0.99 & 0.926 \\
HAQ-DI & $6.02(\mathrm{I} .32-27.32)$ & 0.02 \\
Biologic use & 0.480 & 0.127 \\
Hypertension & $\mathrm{I} .09$ & 0.845 \\
Diabetes & $4.395(\mathrm{I} .58-12.15)$ & 0.0044 \\
Metabolic syndrome & 0 & 0.957 \\
CV events & $\mathrm{I} .652$ & 0.502 \\
Sex F & $0.349(0.138-0.882)$ & 0.027 \\
\hline
\end{tabular}

Abbreviations: $\mathrm{HR}$, hazard ratio; $\mathrm{Cl}$, confidence interval; $\mathrm{RF}$, rheumatoid factor; ACPA, anti-citrullinated cyclic peptides antibodies; SDAI, Simplified Disease Activity Index; HAQ-DI, Health Assessment Questionnaire-Disability Index; CV, cardiovascular.

Finally, we analyzed SMR for different causes of death, recording a high CV SMR (SMR: 2.08; 95\% CI: 1.098-3.628) and a low neoplasm SMR (SMR: 0.207; 95\% CI: $0.0658-0.499)$.

\section{Predictive factors of mortality}

Age at first visit (hazard ratio [HR]: $1.14 ; p \leq 0.0001$ ), diabetes (HR: $4.395 ; p=0.004$ ), and a HAQ value $>1$ (HR: 6.02; $p=0.02$ ) were found to be independent predictors of mortality in univariate analysis as investigated by Cox regression analysis. On the other hand, female sex was found to have a protective role (HR: $0.349 ; p=0.027$ ). On multivariable analysis, the only baseline independent predictor of mortality was age at admission (HR: 1.17 ; 95\% CI: 1.01-1.35; $p=0.026$ ) (Table 3).

\section{Discussion}

To our knowledge, this is the first study devoted to investigate mortality in RA patients from Italy. We retrospectively analyzed the mortality rate in 608 RA patients enrolled over a 6-year period in an Italian rheumatology center. The IMR in our cohort was 0.79 deaths $/ 100$ person-years, ie, quite similar to that reported in the general Italian population, and lower than that reported in other cohorts such as the NOAR registry (Table 2$) \cdot{ }^{17}$

Nevertheless, SMR in our sample of patients with RA was found to be approximately two times higher than that of the general population. In that regard, a recent meta-analysis demonstrated that RA mortality has decreased over the past 50 years but remained higher than in the general population with a meta-SMR of $1.47 .^{6}$
We could not confirm this decrease in mortality rates over time because we did not have previous data in Italy. The absence of differences in the IMR in contrast to the SMR could imply earlier deaths in the RA cohort.

When analyzing causes of death, we found that CV mortality was approximately twice as high as that in the general Italian population (SMR: 2.08; 95\% CI: 1.098-3.628). On the contrary, the mortality for malignancies was lower in our RA patients as compared to general Italian population (SMR: 0.207; 95\% CI: 0.065-0.499), and we did not detect any deaths due to infections. ${ }^{19}$

These intriguing aspects emerging from our study might be explained by the strict follow-up that RA patients undergo when followed at a tertiary center. Actually, new cancers as well as severe infections occurred in our patients, but mortality was lower than expected for both conditions.

Mortality in RA seems to be associated to some prognostic factors such as age, male sex, autoantibody positivity, disease activity, and extra-articular manifestations.,20

In our cohort, male sex, disability, diabetes, and age at admission were found to predict the mortality on univariate analysis.

In addition, we found differences in SMR between the two sexes. These data confirm that male sex is a bad prognostic factor, as has already been published. ${ }^{21}$

Nevertheless, age at admission was found to be the only independent predictor of mortality in multivariable analysis.

\section{Conclusion}

This study supports previous findings that patients with RA have an increased all-cause mortality, ${ }^{21-23}$ and in particular an increased risk death due to $\mathrm{CV}$ causes. ${ }^{4,5}$ Intriguingly, we detected a low death rate due to cancer and infections. These features might indicate that the careful follow-up that RA patients undergo in tertiary centers decreased mortality due to cancer and infections but not CVD. Therefore, they indirectly support the need to improve the management of $\mathrm{CV}$ risk, which is still found to be inadequate. ${ }^{24}$ Our study has some strengths and limitations. It is the first study on mortality in Italian RA patients, the vital status of whom was known in $93 \%$ of patients at the end of follow-up. Nevertheless, it is influenced by the retrospective nature of the analysis and the single-center perspective. A multicentre prospective study is needed to support the preliminary data detected by us.

\section{Disclosure}

The authors report no conflicts of interest in this work. 


\section{References}

1. Pincus T, Callahan LF, Sale WG, et al. Severe functional declines, work disability, and increased mortality in seventy-five rheumatoid arthritis patients studied over nine years. Arthritis Rheum. 1984;27(8):864-872.

2. Leigh JP, Fries JF. Arthritis and mortality in the epidemiological followup to the National Health and Nutrition Examination Survey I. Bull N Y Acad Med. 1994;71(1):69-86.

3. Sokka T, Abelson B, Pincus T. Mortality in rheumatoid arthritis: 2008 update. Clin Exp Rheumatol. 2008;26(5 Suppl 51):S35-S61.

4. Aviña-Zubieta JA, Choi HK, Sadatsafavi M, et al. Risk of cardiovascular mortality in patients with rheumatoid arthritis: a meta-analysis of observational studies. Arthritis Rheum. 2008;59(12):1690-1697.

5. Meune C, Touzé E, Trinquart L, Allanore Y. Trends in cardiovascular mortality in patients with rheumatoid arthritis over 50 years: a systematic review and meta-analysis of cohort studies. Rheumatol Oxf Engl. 2009;48(10):1309-1313.

6. Dadoun S, Zeboulon-Ktorza N, Combescure C, et al. Mortality in rheumatoid arthritis over the last fifty years: systematic review and meta-analysis. Jt Bone Spine Rev Rhum. 2013;80(1):29-33.

7. Salvarani C, Macchioni P, Mantovani W, et al. Extraarticular manifestations of rheumatoid arthritis and HLA antigens in northern Italy. $J$ Rheumatol. 1992;19(2):242-246.

8. Drosos AA, Lanchbury JS, Panayi GS, Moutsopoulos HM. Rheumatoid arthritis in Greek and British patients. A comparative clinical, radiologic, and serologic study. Arthritis Rheum. 1992;35(7):745-748.

9. Cimmino MA, Parisi M, Moggiana G, Mela GS, Accardo S. Prevalence of rheumatoid arthritis in Italy: the Chiavari Study. Ann Rheum Dis. 1998;57(5):315-318

10. Salaffi F, De Angelis R, Grassi W, MArche Pain Prevalence, INvestigation Group (MAPPING) study. Prevalence of musculoskeletal conditions in an Italian population sample: results of a regional community-based study. I. The MAPPING study. Clin Exp Rheumatol. 2005;23(6):819-828.

11. Rossini M, Rossi E, Bernardi D, et al. Prevalence and incidence of rheumatoid arthritis in Italy. Rheumatol Int. 2014;34(5):659-664.

12. Benucci M, Rogai V, Atzeni F, et al. Costs associated with rheumatoid arthritis in Italy: past, present, and future. Clin Outcomes Res CEOR. 2016;8:33-41.
13. Aletaha D, Neogi T, Silman AJ, et al. 2010 rheumatoid arthritis classification criteria: an American College of Rheumatology/European League Against Rheumatism collaborative initiative. Ann Rheum Dis. 2010;69(9):1580-1588.

14. Aletaha D, Smolen J. The Simplified Disease Activity Index (SDAI) and the Clinical Disease Activity Index (CDAI): a review of their usefulness and validity in rheumatoid arthritis. Clin Exp Rheumatol. 2005;23(5 Suppl 39):S100-S108.

15. Wolfe F, Kleinheksel SM, Cathey MA, et al. The clinical value of the Stanford Health Assessment Questionnaire Functional Disability Index in patients with rheumatoid arthritis. J Rheumatol. 1988;15(10):1480-1488.

16. Huang PL. A comprehensive definition for metabolic syndrome. Dis Model Mech. 2009;2(5-6):231-237.

17. Ajeganova S, Humphreys JH, Verheul MK, et al. Anticitrullinated protein antibodies and rheumatoid factor are associated with increased mortality but with different causes of death in patients with rheumatoid arthritis: a longitudinal study in three European cohorts. Ann Rheum Dis. 2016;75(11):1-9.

18. Italian National Institute of Statistics. Available from: www.istat.it. Accessed February 28, 2017.

19. Italian Cancer Registry. Available from: http://www.epicentro.iss.it/ temi/tumori/registri.asp. Accessed February 28, 2017.

20. Symmons DP, Prior P, Scott DL, Brown R, Hawkins CF. Factors influencing mortality in rheumatoid arthritis. J Chronic Dis. 1986;39(2):137-145.

21. Martínez MS, García-Monforte A, Rivera J. Survival study of rheumatoid arthritis patients in Madrid (Spain). A 9-year prospective follow-up Scand J Rheumatol. 2001;30(4):195-198.

22. Kvalvik AG, Jones MA, Symmons DP. Mortality in a cohort of Norwegian patients with rheumatoid arthritis followed from 1977 to 1992. Scand J Rheumatol. 2000;29(1):29-37.

23. Reilly PA, Cosh JA, Maddison PJ, Rasker JJ, Silman AJ. Mortality and survival in rheumatoid arthritis: a 25 year prospective study of 100 patients. Ann Rheum Dis. 1990;49(6):363-369.

24. van Breukelen-van der Stoep DF, Zijlmans J, van Zeben D, et al. Adherence to cardiovascular prevention strategies in patients with rheumatoid arthritis. Scand J Rheumatol. 2015;44(6):443-448.
Open Access Rheumatology: Research and Reviews

\section{Publish your work in this journal}

Open Access Rheumatology: Research and Reviews is an international, peerreviewed, open access journal publishing original research, reports, editorials, reviews and commentaries on all aspects of clinical and experimental rheumatology in the clinic and laboratory including the following topics: Pathology, pathophysiology of rheumatological diseases; Investigation, treatment and management of rheumatological diseases; Clinical trials and novel pharmacological approaches for the treatment of rheumatological disorders. The manuscript management system is completely online and includes a very quick and fair peer-review system, which is all easy to use. Visit http://www.dovepress.com/ testimonials.php to read real quotes from published authors. 